\title{
WHY DO STUDENTS PLAGIARIZE? \\ THE CASE OF MULTICULTURAL STUDENTS IN AN AUSTRALIAN UNIVERSITY IN THE UNITED ARAB EMIRATES
}

\author{
Ajrina Hysaj, Abeer Elkhouly
}

\begin{abstract}
The increase in plagiarism cases among university students is a great concern for educators and policy makers within the federal and private universities in the United Arab Emirates (UAE). Research suggests that students' attitudes toward academic integrity are characteristically more tolerant than the policies already in place in most universities. This assertion can hypothetically intensify the situation that most universities in the UAE are experiencing. Moreover, the presence of a very diverse student body leaves space for validation of the hypothesis, that concepts of plagiarism or academic integrity are seen differently in different cultures; nevertheless, very little research has been carried out to empirically validate such hypothesis. Moreover, current research in this area has usually been conducted in western universities, in western countries and has been focused in a comparison between international and domestic students or native and non-native speakers of English language. As yet, no studies have directly analysed culturally diverse students' attitudes toward plagiarism in their first year of study in a western university in the UAE. This study aimed to measure the students' level of understanding to what plagiarism is. One survey and one quiz were given to 67 students, the data from the surveys was tested against several hypothesis and some descriptive analysis was conducted. The results reveal that students understand the main concepts beyond plagiarism but confuse its application.
\end{abstract}

Key words: Plagiarism, Academic Integrity, Academic Writing Skills, Multicultural Students

\section{Introduction}

Academic dishonesty has been the focus of researchers, educators and curriculum designers for decades (Bowers, 1964; Wells 1993; Scanlon 2003; Zhang et al., 2014). The issue has become even more pressing with the extensive use of the Internet and technology, the prevalence of ghost-writing, and 'cut and paste' techniques (SutherlandSmith, 2008). During this period, studies have progressed following the changes that have happened in societies, education systems, technology and the business world. Scholars were firstly intrigued to understand the reasons why students copy from one another and not study on their own; this later took a different direction with the introduction of online studies and online assessments.

The issue of academic dishonesty has become a worlwide concern due to globalisation of higher education (Terraschke and Wahid, 2011; Taylor, Ryan and Elphinstone, 2020; Duzhyk, 2020). Interestingly, Whitley (1998) in his review of literature established that some of the factors why students cheat were having modest expectations 
of success, "having cheated in the past, studying under poor conditions, holding positive attitudes toward cheating, perceiving that social norms support cheating, and anticipating a large reward for success". (p. 235). Furthermore, according to UNESCO (UNESCO Institute for Statistics, 2020) the number of international students in 2017 jumped to 5.3 million from slightly over 2 million in 2000. The trend of studying abroad does not seem to be on the decrease; therefore, it becomes crucial to understand the attittudes and needs of international students so we can provide them with the adequate tools to study and lessen the need to cheat Van Damme, 2001; Verbik and Lasanowski, 2007; Hysaj and Hamam, 2020).

Issues related to plagiarism or academic misconduct require careful consideration, as they are pivotal in the credibility and reliability of institutions of higher education. In an Australian education context, the issue of understanding foreign students is of a particular concern due to an increased number of international students who study in Australian universities in onshore and offshore campuses, like in China, India, and Malaysia and in the UAE. The University of Wollongong in Dubai, an offshore campus of the Australian University of Wollongong, in the Middle East, which is home to a student body of over 100 nationalities, is highly interested in understanding reasons why students plagiarise.

Substantial studies have analysed the spread of plagiarism in the tertiary level in the UAE (Khan \& Balasubramanian 2012; Khan 2010; Khan, al-Qaimari \& Samuel 2007). The lack of academic integrity in the tertiary level was seen due to a variety factors, e.g. spread of technology, ghost writing, E-cheating to name a few. Nevertheless, the focus of these studies was not to analyse the effects of academic writing skills and the correlation that it has with the plagiarism instances in the region. Therefore, the authors of this study hold the opinion that it becomes important to analyse and understand the correlation between academic writing skills and cases of plagiarism.

Curtis and Vardanega (2016) analysed the attitudes of three similar groups of students at the same university on three occasions, each separated by a time interval of five years (2004, 2009, and 2014). The assessed traits were self-reported engagement in plagiarism, awareness of academic misconduct and attitudes towards plagiarism. Unpredictably the analysed data from this study revealed positive development with regards to reduction of numerous forms of plagiarism due to increase in understanding plagiarism (Curtis \& Vardanega, 2016) and entitled the technological and educational initiatives for counteracting the potential risk of plagiarism from online sources.

Song-Turner (2008), after interviewing many foreign students, found that some of reasons why international students plagiarise include language challenges, lack of skill sets, and inability of producing a text similar to that of a native speaker. Our university as an offshore branch of an Australian university sees it constantly crucial to understand the web of perceptions of international students towards plagiarism. This becomes even more evident when valuing the importance given by the Australian government, to attract these students to the onshore and offshore Australian universities and can strengthen universities marketing efforts in attracting foreign students while emphasising high levels of academic integrity.

Conversely, Song-Turner (2008) recorded that lack of understanding of foreign students resulted in many cases of plagiarism in two major Australian universities in 
the year 2005; University of Wollongong recorded 134 and the University of Technology, Sydney recorded 362 counts of plagiarism. Moreover, the same study found that almost 3500 students have been caught plagiarising or cheating across eight Australian universities since 2001. Nevertheless, it is worth mentioning that there was no evidence that overseas students were the only ones who tended to plagiarise but it does indicate that the students' influx has a fair share in the rise of plagiarism as a phenomenon.

It is worth mentioning that this trend is not only prevalent among undergraduate students but also among doctoral students from different countries(Moten, 2014; Yukhymenko-Lescroart, 2014). Consequently, the combination of cultural and language issues, increases the potential for plagiarism to take place (Pecorari \& Petrić, 2014). Findings of Heckler and Forde (2015) indicate that creating awareness about plagiarism and more importantly facilitating the process of learning can potentially bring changes to values and beliefs supporting a long lasting learning culture. Therefore, the notion of plagiarism is open to a range of interpretations because of different stakeholders involved in teaching and learning in higher education; the policy makers, management, faculty and students. Understanding the university policies on plagiarism, understanding students' attitudes towards academic misconduct/academic integrity and matching the parameters of expectations of both parties can ensure a decrease in the reported cased of plagiarism.

Gullifer and Tyson (2014) reported in their study that out of the 3405 students who took part in their study, only half had read the institutional policy on plagiarism/academic integrity resulting in not being aware of what continues plagiarism in the first place. This clears the path for a systematic and progressive educative approach of creating awareness regarding plagiarism/academic integrity and implications of its infringement. A qualitative research by Devlin and Gray (2007) looked at principal factors behind students' inclination to plagiarise and concluded that students' lack of understanding plagiarism, poor academic skills, personality factors and external pressures were partly to be blamed. Therefore, better engagement with students is seen as an effective way toward minimising and marginalising instances of plagiarism.

The rationale behind reasons why students plagiarise, encompasses the ways students think and behave under certain circumstances that could be due to cultural, psychological or any other individual related factors (Park, 2003; Bamford \& Sergiou 2005; Batane, 2010; Alghamdi, Hussain \& Al-Hattami, 2018). Moreover, as Devlin and Gray (2007) rightly mentioned although, academic misconduct is present in most universities, a strategy of non-tolerance or a zero percentage plagiarism, is not applied because students are quite often viewed as customers. Therefore, the most efficient and productive way is to ensure that our students understand plagiarism, implications of its infringement and avoid opting for it by empowering themselves with the appropriate sets of language and writing skills (Curtis \& Vardanega, 2016; Lea \& Street, 1998).

The issues of inclusiveness should be taken into consideration when outlining curriculum material and assessment tasks (Lea \& Street, 1998; Hysaj \& Hamam, 2020). In other words, definitions of appropriate classroom material and assessment tasks should be based on the students' needs and be inclusive of their their cultural backgrounds as much as theinstitutional culture of the universities. For instance, Bretag et al. (2014) proposed the need to provide students with academic integrity training in the form of 
'hands-on activities, engaging activities, repeated and reconfigured in various media and forums throughout the student programme' which potentially can provide an environment of a strong culture integrity in the institutions.

Furthermore, Etter et al. (2006) found that the attitude towards academic dishonesty did not differ between students who had idealistic behaviour and the ones who did not value the ethical principles as an essential trait of human personality. As a result, both groups considered it justifiable to utilise information technology as a tool to escape academic assignments and did not view it as unethical since it does not involve harming other people.

\section{Literature Review}

\subsection{Cultural Factors}

Previous studies conducted by Batane (2010), Petrić (2012), Ison (2018), and Foltýnek and Dlabolová (2020) have analysed issues related to plagiarism and academic integrity in certain countries or cultures. However, a study analysing the attitudes of culturally diverse students in an offshore western university in the UAE has yet to be conducted.

Ison (2018) analysed in a quantitative study; the ways academic integrity is dealt with in different cultures and its subsequent occurrence cases. His research focused on the possible differences among cultures and the ways in which cultures view plagiarism or academic misconduct. It is worth mentioning that he analysed doctoral and master's theses students; hence, his study is not considered as an empirical evidence of the same student's attitudes towards plagiarism; when they were in their undergraduate studies.

Interestingly, the findings of this study aligned with those of Rawwas et al. (2004) and Heckler and Forde (2015), which supported the considerable differences in the approaches towards plagiarism; demonstrated by the American and Chinese students in the study of Rawwas et al. (2004) and those of American students, mainly Caucasian descents in the study of Heckler and Forde (2015). Needless, to say that the three mentioned studies as well as the study by Ehrich et al. (2016) identified 'poor language and academic skills' as the main culprit for increased cases of plagiarism among cultures whose first language is not English; concluding that the tendency to plagiarise is due to the lack of English language proficiency.

Research on student motivation and student engagement has offered substantial evidence for the application of a continuous self-efficacy among students as a key to a successful and inclusive learning experience. Linnenbrink and Pintrich (2003) analyse the self-efficacy by focusing on its potential to facilitate behavioural, cognitive and motivational engagement in the classroom subsequently resulting in life-long learning experiences. Multicultural students are a hybrid of multiple of identities; the home and the educational environments named as the most substantial and distinctive ones. Culturally responsive educators are in the authority of helping international students nurture their individual cultural identities while assessing school curriculum, successively creating individuals who are able to navigate productively in multiple communities (Rueda et al., 2007). 
Furthermore, students' perceptions of the dominant culture of the higher education institutions need to be understood so issues in regards to academic misconduct do not arise due to unawareness of institutional values and beliefs even if this requires negation of individual cultural values often used as justifications for plagiarizing (Heckler and Forde, 2015). A recent study by Ehrich et al. (2016), analysing Australian and Chinese students in their native countries, highlights that undergraduate students in both countries lack understanding of plagiarism and plagiaristic behaviours. The same study suggests the need for unambiguous instruction of the academic skills; facilitating development of critical and analytical understanding of undergraduate students so they can engage in the research process without improperly using others' ideas.

Academic dishonesty is a major challenge in the Arabian Gulf, similar to that of educational institutions worldwide (Thomas et al., 2014; Razek, 2014; McCabe et al., 2008). All the three above studies point out that the distinguished rationale for presence of academic dishonesty in the Middle East; which is strongly influenced by the norms of the collectivist society. As mentioned in the study by Singelis and Brown (1995) examination of the behaviour of individual needs to be correlated with the culture they belong to and, (Thomas et al., 2014) if possible a reasonable correlation needs to be found between the culture and the way students belonging to same culture expect to be assessed. The oral assessment provided as an alternative of a written assessment, in an experiment that took place in a university in the United Arab Emirates, provided enough evidence for a validation of the originality of student work, while assisting assessment in an approach that resonates with the region's own educational traditions and collectivist cultural norms (Thomas et al., 2014).

A study by Jian, Marion and Wang (2019) found that academic and cultural backgrounds of Chinese international students, substantially influenced by the Confucian philosophy, aim for prevalence of collectivism and social order even when studying abroad. These set of values create cultural differences when studying abroad and having to take individually self-reflected decisions concerning plagiarism or academic misconduct. Therefore, these students will need to navigate their way between high integrity expectations present the institutions in host countries and their individual cultural beliefs. This study is of a particular interest for the UAE private universities, which have seen a considerable increase in the number of Chinese students studying in the country.

The native population of the UAE is predominantly Muslim and so is the majority of foreign students studying in the private universities in the country. Therefore, it becomes valuable to analyse previous research conducted in other Muslim countries. A study by Moten (2014) asserts that from an Islamic perspective, academic dishonesty is a form of cheating and it is morally and ethically unacceptable and yet there is very little research done to analyse the issue of plagiarism in regards to students and faculty attitudes in relation to plagiarism in the Middle East and the wider Muslim world. According to Moten (2014) institutions in Malaysia consider plagiarism as immoral and against the law and focus on development of writing and research skills.

Furthermore, a study conducted to compare the Ukrainian and American educational systems found that the ethical systems implemented in schools have to do with 
the approaches taken by faculty and students. Nevertheless, the attitude towards honesty, unilateral cheating, collective cheating, falsification, gaining favouritism, and performing extra work to receive better grades are more relevant to a cross-cultural study rather than an educational system' study (Yukhymenko-Lescroart, 2014, p. 29). Hence, the differences noticed in Ukrainian and American educational systems have to do with differences between both cultures much more than they have to do with differences between their respective education systems (Yukhymenko-Lescroart, 2014).

\subsubsection{Development of English Writing Skills - More than a daunting task or a fun activity}

Non-native speakers of English language must be applauded for taking up the challenge of learning English language skills, then progressing to master the Academic English language skills, which are challenging even for native speakers of English language. Moreover, they move forward to mastering the critical and analytical thinking in English language, gaining awareness of paraphrasing and summarizing in English language and finally producing a piece of writing which has all the qualities of a good one and yet more is marked against a marking criteria that has been designed for native speakers of English language

In the process of becoming near native speakers of English language, international students are challenged with extensive diversity issues related to considerable differences in linguistic, cultural, and academic background experiences (Markham \& Gordon 2007). Very often undergraduate and post graduate students find themselves lacking the adequate academic writing skills and are confused about the concepts and usage of in-text citations, reference lists and furthermore the different referencing systems. This gets even more complicated when students need to use different referencing systems in academic study skills classes and a more discipline related one in their discipline related subjects. Hence, the writing tasks become even more daunting and students may lose interest all together. It is crucial that we as educators try to find different ways of helping students master their academic writing skills without compromising on quality, integrity or institutional culture.

A case study by Prescott (2016) suggests collaborative work as a possible approach towards better academic writing skills. The ongoing research on second language (L2) acquisition, as well as in its writing and applied linguistic perspectives goes back to the mid 1980's (Pecorari \& Petrić, 2014). In the field of L2, a myriad of topics that has emerged through the decades; differences in concepts of understanding plagiarism between faculty and students, development of writing skills in L2 students, ways how disciplines differ in perceptions of plagiarism, and the roles of culture and electronic media (Pecorari \& Petrić, 2014, p. 73) require further analysis to be understood. Liu (2005) holds the opinion that the lack of language and writing skills of L2 students provide a platform for unintentional plagiarism and development of those applied skills has the potential to reduce the occurrence of academic misconduct. Resorting to plagiarism seems to be more a case of desperation rather than that of a willingly taken decision. Exploring ways to facilitate the development of writing skills has direct pedagogical implications on students' learning (Liu, 2005). 
Gallant (2008, p. 112) argues that new teaching and learning approaches are needed, aiming learning at avoidance of plagiarism rather than curbing cheating. She debates that this could be achieved through "fostering a learning-oriented environment, improving instruction, enhancing institutional support for teaching and learning and reducing institutional constraints to teaching and learning" (Gallant, 2008, p. 89). Facilitating the atmosphere for teaching and learning can be attained by improving instruction and fostering learning orientations (Gallant, 2017).

West (2012) emphasised that academic writing is not an innate skill and hence, it needs to be developed. Students across all disciplines seem to be resilient to the prerequisite of developing writing skills alongside their discipline related knowledge acquisition. A way of tackling such issue could be 'writing across the curriculum' (WAC) by addressing issues of adequately teaching academic writing skills while emphasising 'writing in the disciplines' (WID) (Buzzi et al., 2012).

McDonald, Moorhead and Colburn (2015) are of the same view as their study on counselling students emphasises the need of a multi-layered approach, focusing on the development of adequate academic writing skills while applying the WID approach in teaching. Another study by Smith and Humphreys (2017) noted that academic writing, research skills development along with awareness of academic dishonesty are very important for post-graduate students, despite effectively displaying a higher level of maturity in regards to their studies, compared to their undergraduate counterparts. Academic writing and application of referencing skills take time to master and sharpen, but the process could be made simpler by giving emphasis to the development of critical and analytical writing abilities (Hysaj et al., 2018; Hysaj et al., 2019) instead of addressing and tacking plagiarism as a phenomenon (Vardi, 2012). By doing so we encourage students to focus on their personal and academic growth rather than the opposite. As educators, we should emphasise the necessity to analyse ways and approaches to help our students develop academic writing skills. Approaches could be of a pedagogical nature, content wise and building of appropriate vocabulary and grammar skills to empower students with adequate tools that aid the avoidance of plagiarism.

\section{Research Methodology}

\subsection{Research Aim and Analysis}

This study was conducted to measure the students' level of understanding plagiarism after being lectured by different teachers. Participants were all international students from the age group of 18 to 22 . The surveys were anonymous and students were informed that their confidentiality was of utmost importance. One worksheet of eight questions was given to the students; the questions had three options (yes, no or not sure). The questions were based on definition of plagiarism and application of avoidance of plagiarism in a written format. Students were asked about different situations if they constitute plagiarism. The other survey was in the form of a quiz; the quiz had 11 questions of true or false answers. The data collected from the worksheet was analysed using descriptive statistics to indicate proportion of students who were 
able to understand the studied concept. The quiz data results was tested to verify the hypothesized values for the average number of students who were able to get the correct answer to quiz questions.

The sample consists of 67 students, 18-22 age group; male and female from different study disciplines and different study levels. Cronbach's Alpha was calculated for both surveys to check the reliability of students' answers. The percentages' of students who answered the worksheet correctly were calculated. Student sample proportions from the quiz were calculated and compared to the hypothesized value in order to decide whether to reject the null hypothesis. The analysis used is z-test for the proportion at level of significance 0.05 , one tail test with critical value $Z=-1.645$. The sampling distribution of proportion to be approximately normal was checked [ref].

Cronbach's Alpha was calculated to check the reliability of students' answer; SPSS was used for the calculations.

\section{Results and Discussion}

Table 1 shows the results of the worksheet and the reliability test result.

Table 1

Results of the worksheet and the reliability test result

\begin{tabular}{|c|c|c|c|c|c|}
\hline \multicolumn{6}{|c|}{ Response } \\
\hline Measures & No & Yes & Not sure & $\begin{array}{l}\text { \% Correct } \\
\text { response }\end{array}$ & $\begin{array}{l}\text { Cronbach's } \\
\text { Alpha }\end{array}$ \\
\hline & & & & & 0.935 \\
\hline Copying or sharing assignments & 2 & 63 & 2 & 94.0 & \\
\hline Failing to cite a commonly known source & 17 & 39 & 11 & 58.2 & \\
\hline Failing to cite a statistic & 7 & 53 & 7 & 79.1 & \\
\hline $\begin{array}{l}\text { Paraphrasing the work of others you find in } \\
\text { books, magazines, websites without } \\
\text { documentation }\end{array}$ & 9 & 51 & 7 & 76.1 & \\
\hline $\begin{array}{l}\text { Asking another student to write a paper for } \\
\text { you }\end{array}$ & 11 & 53 & 3 & 79.1 & \\
\hline $\begin{array}{l}\text { Copying material from another source, citing } \\
\text { the material in your bibliography, but leaving } \\
\text { out an in-text citation }\end{array}$ & 11 & 42 & 14 & 62.7 & \\
\hline $\begin{array}{l}\text { Listing works in your bibliography that you } \\
\text { have not used or read }\end{array}$ & 29 & 28 & 10 & 41.8 & \\
\hline $\begin{array}{l}\text { Mixing the words of an author with your own } \\
\text { without documentation }\end{array}$ & 11 & 46 & 10 & 68.7 & \\
\hline
\end{tabular}

Correct response

The students' responses were consistent for the measures in table 1, Cronbach's Alpha (o.935). The results show $94 \%$ of the students understand that Copying or sharing assignments is considered plagiarism, $79 \%$ of the students understand that failing to cite a statistic or asking another student to write a paper for them is plagiarism. $76 \%$ of them interpreted paraphrasing the work of others they find in books, magazines, 
websites without documentation as plagiarism, number of students who found mixing the words of an author with your own without documentation is plagiarism $68 \%$ while $62 \%$ considered copying material from another source, citing the material in a bibliography, but leaving out an in-text citation is plagiarism. This low response from the student means they need to understand copying ideas or concepts in their own words still need citation also teachers need to explain to students with examples how to cite a resource in text and in their list of references. It is evident that the students do not know what is meant by common source as $58 \%$ only considered failing to cite it is plagiarism while $79 \%$ for failing to cite a statistic. Students need to be aware by citing a resource not used gives more value to their work, which is considered plagiarism as $41 \%$ only consider it.

The following true or false quiz was designed to measure the depth of students' understanding to plagiarism:

1. You do not have to quote famous sayings or proverbs (example: Early to bed and early to rise makes a man healthy, wealthy, and wise) because they are common knowledge (Q1).

2. Copying and pasting from the Internet can be done without citing the Internet page, because everything on the Internet is common knowledge and can be used without a citation (Q2).

3. If you just borrow someone's idea and not their exact words, you do not have to quote or cite anything (Q3).

4. If a writer copies and pastes words and ideas from the internet, they do not have to quote or cite anything. After all, anyone can google information on the internet and find the same facts $\left(\mathrm{Q}_{4}\right)$.

5. Giving incorrect information about the source of a quotation is considered (Q5).

6. Writers cite sources because it is the only way to use other people's work without plagiarizing (Q6).

7. As long as you have the author's name, you can leave out the page number title of the work in the citation. Only one part of the source needs to be revealed in a paper in order to give proper credit $\left(Q_{7}\right)$.

8. If a student copies another student's homework, this is not considered plagiarism. The students are not famous people and the homework was not published, so it is not considered plagiarizing (Q8).

9. Using a few phrases from an article and mixing them in with your own words is plagiarism (Q9).

10. If you quote your friend in an interview, you do not have to cite him or her or use quotation marks (Q10).

11. Changing a few words, but copying the same sentence structure and organization of a person's piece is considered plagiarism (Q11).

Table 2 shows the number of students in the sample who responded correctly to the quiz, the percentage of this response, the hypothesised student population proportion 
Table 2

Correct responses to the quiz

\begin{tabular}{|c|c|c|c|c|c|c|}
\hline \multicolumn{7}{|c|}{ Response } \\
\hline Measures & True & False & $\begin{array}{c}\text { \% Correct } \\
\text { response }(p)\end{array}$ & $\begin{array}{c}\text { \% Hypothesized } \\
\text { values }(\boldsymbol{\pi})\end{array}$ & Z-test & $\begin{array}{c}\text { Cronbach's } \\
\text { Alpha }\end{array}$ \\
\hline & & & & & & 0.97 \\
\hline Q1 & $\mathbf{3 6}$ & 31 & 53.7 & 43 & 1.77 & \\
\hline Q2 & 6 & $\mathbf{6 1}$ & 91.0 & 83 & 1.75 & \\
\hline Q3 & $\mathbf{2 5}$ & 42 & 37.3 & 28 & 1.70 & \\
\hline Q4 & 11 & $\mathbf{5 6}$ & 83.6 & 74 & 1.79 & \\
\hline Q5 & $\mathbf{5 2}$ & 15 & 77.6 & 68 & 1.69 & \\
\hline Q6 & $\mathbf{5 0}$ & 17 & 74.6 & 65 & 1.65 & \\
\hline Q7 & 8 & $\mathbf{5 9}$ & 88.1 & 80 & 1.65 & \\
\hline Q8 & 5 & $\mathbf{6 2}$ & 92.5 & 85 & 1.73 & \\
\hline Q9 & $\mathbf{3 6}$ & 31 & 53.7 & 43 & 1.77 & \\
\hline Q10 & 25 & $\mathbf{4 2}$ & 62.7 & 52 & 1.75 & \\
\hline Q11 & $\mathbf{5 8}$ & 9 & 86.6 & 78 & 1.69 & \\
\hline
\end{tabular}

Correct response

who would respond correctly, the corresponding Z-test values and the reliability test value.

The null hypothesis is rejected at the hypothesized population proportion. The test statistic value were calculated using the formula:

$$
\text { Z-test }=\frac{p-\pi}{\sqrt{\pi(1-\pi) / 67}}
$$

The hypothesised population proportions are the maximum proportions who can get the correct answers to the quiz.

$85 \%$ of students knew that copying another student's work is plagiarism. $83 \%$ of the students knew that information from the internet should be cited while $74 \%$ understood that writers need to cite the accessed work from the internet \& $65 \%$ of the students knew that writers need to cite any sources used by them. $80 \%$ of the student population knew what are the details needed to cite a journal paper, $78 \%$ of the students understand that paraphrased work should be cited, $68 \%$ of the population knew that they needed to give correct information about their sources, and $52 \%$ of students understood that they needed to cite friend interview. This low response indicated that students were unaware of the sources that are academically appropriate to be used and eventually to be cited. Only $43 \%$ of the population knew that they need to cite famous sayings and or passages taken from a journal article. This low response could again be explained as unawareness from the side of students. Moreover, $28 \%$ of the cohort knew that is was not necessarily to cite borrowed ideas. This very low response indicates that students did not understand the difference between 
borrowing ideas and copying them. The high values of reliability show high consistency in students' response, which reflect that the concepts that understood by the students are common, and the misinterpreted ones. This can guide teachers to focus on points that will help students to avoid actions that lead to plagiarism. Furthermore, teachers should find ways of explaining concepts by practice rather than by using theory.

\section{Recommendations and Conclusion}

Lack of resourcefulness and imagination on educators' part, often leads to plagiarized work from students; therefore, educators should put in responsible efforts to formulate out-of-the-box projects that allow students to utilize their own cognitive skill set. Devising assignments or tasks that depend on original expression, rather than based on previous or current research topics could reduce the plagiarism activities. Universities across UAE should also build strategies that ensure students' understanding of institutions' plagiarism policies and are clear over various plagiarism related issues. The consequences of plagiarism could be delivered to the students through active discussions, written guidelines and practices in identifying proper and improper citation. The scope of future research could be to examine the ethical values been taught and maintained in high schools across UAE. Moreover, an investigation of how parental values and teachings at home affects students' mind-set towards classroom activities, would be helpful in understanding the issues that lead to plagiarism. Furthermore, a deeper insight into this area of concern; could further allow educators to discuss and improve students' attitude towards plagiarism. Finally, a statistical analysis across various other local and international universities within UAE pertaining to plagiarism could further complement the results presented within this paper.

In conclusion, though the research studies indicate that students tend to understand the meaning of plagiarism and its different forms, this study found that such reinforcement is constantly required. In addition, regardless of the diverse student body, location and local culture within the university, the students tend to utilize similar plagiarism techniques. Educators are required to employ a variety of strategies to prepare students with the right graduate attributes, shape the mind-set of students and equip them with the correct writing skills and practices.

\section{References}

Al Ghamdi, A. K. H., Hussain, I. Y., \& Al-Hattami, A. A. (2018). Plagiarism in Saudi Arabian Public Higher Education: Reasons and Solutions, Asian Journal of Arts, Humanities and Social Studies, vol. 1, no. 1 , pp. $40-48$.

BAMFORD, J., \& SERGIOU, K. (2005). International students and plagiarism: An analysis of the reasons for plagiarism among international foundation students, Investigations in university teaching and learning, vol. 2, no. 2, pp. 17-22.

BatAnE, T. (2010). Turning to Turnitin to fight plagiarism among university students, Journal of Educational Technology \& Society, vol. 13, no. 2, pp. 1-12.

Bretag, T., Mahmud, S., Wallace, M., Walker, R., McGowan, U., East, J., Green, M., Partridge, L., \& JAMES, C. (2014). Teach us how to do it properly! An Australian academic integrity student survey. Studies in Higher Education, vol. 39. no. 7, pp. 1150-1169. 
Buzzi, O., Grimes, S., \& Rolls, A. (2012), Writing for the discipline in the discipline?, Teaching in Higher Education, vol. 17, no. 4, 479-484.

Bowers, W. J. (1964). Student dishonesty and its control in college, Bureau of Applied Social Research, Columbia University.

CURTis, G. J., \& VARDANEGA, L. (2016). Is plagiarism changing over time? A 10-year time-lag study with three points of measurement, Higher Education Research \& Development, vol. 35, no. 6, pp. 1167-1179.

Devlin, M., \& Gray, K. (2007). In their own words: A qualitative study of the reasons Australian university students plagiarize, High Education Research E Development, vol. 26, no. 2, pp. 181-198.

Duzнук, N. (2020). Employing an ethical approach to writing in academic settings.

EtTer, S., Cramer, J. J., \& FinN, S. (2006). Origins of academic dishonesty: Ethical orientations and personality factors associated with attitudes about cheating with information technology. Journal of Research on Technology in Education, vol. 39, no. 2, pp. 133-155.

Ehrich, J., Howard, S. J., Mu, C., \& Bokosmaty, S. (2016). A comparison of Chinese and Australian university students' attitudes towards plagiarism, Studies in Higher Education, vol. 4, no. 1, pp. $231-246$.

Fenton-Smith, B., \& Humphreys, P. (2017). Language specialists' views on the academic language and learning abilities of English as an additional language postgraduate coursework students: towards an adjunct tutorial model, Higher Education Research E Development, vol. 36, no. 2, pp. $280-296$.

FoltýneK, T., \& DlabolovÁ, D. (2020). Academic integrity in Eastern Europe: beyond corruption and plagiarism, In A Research Agenda for Academic Integrity. Edward Elgar Publishing.

Gallant, T. B. (2008). Academic Integrity, Jossey-Bass.

Gallant, T. B. (2017). Academic integrity as a teaching E learning issue: From theory to practice. Theory Into Practice, vol. 56, no. 2, pp. 88-94.

Gullifer, J. M., \& Tyson, G. A. (2014). Who has read the policy on plagiarism? Unpacking students' understanding of plagiarism, Studiesin Higher Education, vol. 39, no. 7, pp. 1202-1218.

HeCKler, N. C. AND Forde, D. R. (2015). The role of cultural values in plagiarism in higher education. Journal of Academic Ethics, vol. 13, no. 1, pp. 61-75.

Hysaj, A., Elkhouly, A., Qureshi, A. W., \& Abdulaziz, N. (2018). December. Analysis of Engineering Students' Academic Satisfaction in a Culturally Diverse University, In 2018 IEEE International Conference on Teaching, Assessment, and Learning for Engineering (TALE) (pp. 755-76o). IEEE.

Hysaj, A, Elkhouly, A, Qureshi, A. W. and Abdulaziz, N. A. (2019). Study of the impact of tutor's support and undergraduate student's academic satisfaction. Am. J. Hum. Soc. Sci. Res, vol. 3, no. 12, pp. $70-77$.

HysaJ, A., \& HAMAM, D. (2020). July. Does Delivery Method Matter for Multicultural Undergraduate Students? A Case Study of an Australian University in the United Arab Emirates. In International Conference on Human-Computer Interaction (pp. 538-548). Springer, Cham.

Ison, D. C. (2018). An empirical analysis of differences in plagiarism among world cultures. Journal of Higher Education Policy and Management, vol. 40, no. 4, pp. 291-304.

JiAn, H., MARION, R., \& WANG, W. (2019). Academic Integrity from China to the United States: The Acculturation Process for Chinese Graduate Students in the United States. Ethics \& Behavior, vol. 29, no. 1, pp. 51-70.

Khan Z. R., \& Balasubramanian, S. (2012). Students go click, flick and cheat... e-cheating, technologies and more, Journal of Academic and Business Ethics, vol. 6, p. 1.

KHAN, Z. R. (2010). E-cheating in the UAE: a critical review of existing literature. 
Khan, Z. R., Al-QAimari, G., \& SAmuel, S. D. (2007). Professionalism and ethics: is education the bridge?, In Information Systems and Technology Education: From the University to the Workplace (pp. 214-241), IGI Global.

LeA, M. R., \& Street, B. V. (1998). Student writing in higher education: An academic literacies approach, Studies in higher education, vol. 23, no. 2, pp. 157-172.

Linnenbrink, E. A., \& Pintrich, P. R. (2003). The role of self-efficacy beliefs in student engagement and learning in the classroom, Reading E Writing Quarterly, vol. 19, no. 2, pp. 119-137.

LIU, D. (2005). Plagiarism in ESOL students: Is cultural conditioning truly the major culprit?. ELT journal, vol. 59 , no. 3, pp. 234-241.

MARKhAM, P., \& GORDON, K. (2007). Challenges and instructional approaches impacting the literacy performance of English Language Learners, Multiple Voices for Ethnically Diverse Exceptional Learners, vol. 10, no. 1, pp. 73-81.

McCabe, D. L., Feghali, T., \& Abdallah, H. (2008). Academic dishonesty in the Middle East: Individual and contextual factors, Research in Higher Education, vol. 49, no. 5, pp. 451-467.

McDonald, K. E., Moorhead, H. J., \& Neuer Colburn, A. A. (2015). Teaching Writing Skills to Counseling Students for Clinical Competence and Professional Advocacy, Journal of Counselor Leadership and Advocacy, vol. 2, no. 1, pp. 80-91.

Moten, A. R. (2014). Academic dishonesty and misconduct: Curbing plagiarism in the Muslim world, Intellectual discourse, vol. 22, no. 2, p. 167.

PARK, C. (2003). In other (people's) words: Plagiarism by university students - literature and lessons. Assessment $\mathcal{E}$ evaluation in higher education, vol. 28, no. 5, pp. 471-488.

Pecorari, D., \& Petrić, B. (2014). Plagiarism in second-language writing, Language Teaching, vol. 47, no. 3 , pp. 269-302.

Petrić, B. (2012). Legitimate textual borrowing: Direct quotation in L2 student writing. Journal of Second Language Writing, vol. 2, no. 2, pp. 102-117.

PrescotT, L. (2016). Using collaboration to foster academic integrity, Open Learning: The Journal of Open, Distance and e-Learning, vol. 31, no. 2, pp. 152-162.

RuedA, R., Lim, H., \& Velasco, A. (2007). Cultural accommodations in the classroom: An instructional perspective. Multiple Voices for Ethnically Diverse Exceptional Learners, vol. 10, no. 1-2, pp. 61-72.

RazEK, N. (2014). Academic integrity: A Saudi student perspective, Academy of Educational Leadership Journal, vol. 18, no. 1.

Rawwas, M. Y., Al-Khatib, J. A., \& Vitell, S. J. (2004). Academic dishonesty: A cross-cultural comparison of US and Chinese marketing students, Journal of Marketing Education, vol. 26, no. 1, pp. 89-10o.

SCANLON, P. M. (2003). Student online plagiarism: how do we respond?, College Teaching, vol. 51, no. 4, pp. 161-165.

SONG-Turner, H. (2008). Plagiarism: Academic dishonesty or 'blind spot' of multicultural education?, Australian Universities' Review, vol. 50, no. 2, p. 39.

Singelis, T. M., \& Brown, W. J. (1995). Culture, self, and collectivist communication: Linking culture to individual behaviour, Human communication research, vol. 21, no. 3, pp. 354-389.

Sutherland-SMith, W. (2008). Plagiarism, the Internet, and student learning: Improving academic integrity, Routledge.

TAYLOR, S., RYAN, M., \& ELPHINSTONE, L. (2020). Employing culturally responsive pedagogy and technologies to re-frame diverse team work challenges as common and improvable: Multiculturality \& Inclusion. EDULEARN2o Proceedings. 
TerraschKe, A., \& WAHID, R. (2011). The impact of EAP study on the academic experiences of international postgraduate students in Australia. Journal of English for Academic Purposes, vol. 10, no. 3, pp. 173-182.

Thomas, J., Raynor, M., \& McKinnon, M. (2014). Academic integrity and oral examination: an Arabian Gulf perspective, Innovations in Education and Teaching International, vol. 51, no. 5, pp. 533-543.

VARDI, I. (2012). Developing students' referencing skills: a matter of plagiarism, punishment and morality or of learning to write critically?, Higher Education Research \& Development, vol. 31, no. 6, pp. 921-930.

UNESCO InSTitute for STATistics. (2020). Data Center: Student mobility country of origin, 2020. Accessed at http://stats.uis. unesco.org/unesco/TableViewer/document. aspx?ReportId=136 on August 5th, 2020

VAn DAmme, D. (2001). Quality issues in the internationalisation of higher education, Higher education, vol. 41, no. 4, pp. 415-441.

Verbik, L., \& LASANOWSKi, V. (2007). International student mobility: Patterns and trends, World Education News and Reviews, vol. 20, no. 10, pp. 1-16.

Wells, D. (1993). An account of the complex causes of unintentional plagiarism in college writing. WPA: Writing Program Administration, vol. 16, no. 3, pp. 59-71.

WEST, A. (2012). Formative evaluation of the transition to postgraduate study for counselling and psychotherapy training: Students' perceptions of assignments and academic writing. Counselling and psychotherapy research, vol. 12, no. 2, pp. 128-135.

Whitley, B. E. (1998). Factors associated with cheating among college students: A review. Research in higher education, vol. 39, no. 3, pp. 235-274.

Yukhymenko-Lescroart, M. A. (2014). Ethical beliefs toward academic dishonesty: a cross-cultural comparison of undergraduate students in Ukraine and the United States, Journal of Academic Ethics, vol. 12, no. 1, pp. 29-41.

Zhang, F., Wu, D., LiU, P., \& ZhU, S. (2014). November. Program logic based software plagiarism detection. In 2014 IEEE 25 th International Symposium on Software Reliability Engineering (pp. 66-77). IEEE.

\section{Authors}

Ajrina Hysaj, University of Wollongong in Dubai, Block 14 Knowledge Park, Umm Suqueim 20183 Dubai, United Arab Emirates, e-mail: AjrinaHysaj@uowdubai.ac.ae

Abeer Elkhouly, Faculty of Engineering and Information Sciences, UOWD College Dubai, United Arab Emirates 